\title{
Médiévales
}

Langues, Textes, Histoire

$64 \mid$ printemps 2013

Temporalités de l'Égypte

Jean-Pierre BARRAQUÉ et Béatrice LEROY, La Majesté en Navarre et dans les couronnes de Castille et d'Aragon à la fin du Moyen Âge

Limoges, Presses universitaires de Limoges, 2011, 184 p.

\section{Hélène Sirantoine}

\section{(2) OpenEdition}

Journals

Édition électronique

URL : https://journals.openedition.org/medievales/7043

DOI : 10.4000/medievales.7043

ISSN : 1777-5892

Éditeur

Presses universitaires de Vincennes

Édition imprimée

Date de publication : 1 juillet 2013

Pagination : 205-207

ISBN : 978-2-84292-371-6

ISSN : 0751-2708

Référence électronique

Hélène Sirantoine, « Jean-Pierre barraqué et Béatrice Leroy, La Majesté en Navarre et dans les couronnes de Castille et d'Aragon à la fin du Moyen Âge », Médiévales [En ligne], 64 I printemps 2013, mis en ligne le 09 septembre 2013, consulté le 22 avril 2022. URL : http://journals.openedition.org/medievales/7043 ; DOI : https://doi.org/10.4000/medievales.7043

Ce document a été généré automatiquement le 22 avril 2022.

Tous droits réservés 


\section{Jean-Pierre BARRAQUÉ et Béatrice} LEROY, La Majesté en Navarre et dans les couronnes de Castille et d'Aragon à la fin du Moyen Âge

Limoges, Presses universitaires de Limoges, 2011, 184 p.

\section{Hélène Sirantoine}

1 Avec ce petit livre, Jean-Pierre Barraqué et Béatrice Leroy prolongent la série des ouvrages publiés aux Presses universitaires de Limoges qui donnent à connaître au public, à grand renfort de traductions fort appréciables, l'histoire hispano-chrétienne au Moyen Âge au travers de ses sources écrites. Dans la veine de leur précédente collaboration autour Des écrits pour les rois ${ }^{1}$, c'est à la réflexion sur la Majesté royale qu'est consacré le présent volume. Il privilégie pour cette fois une chronologie partant du milieu du XIII ${ }^{\mathrm{e}}$ siècle.

2 La première partie - la plus suggestive selon nous - s'intéresse à la définition théorique de la Majesté - entendue ici comme «l'expression visible de la souveraineté » (p. 7) telle qu'elle apparaît dans trois catégories d'écrits. Ce sont d'abord ceux qui émanent de la maison royale : le modèle du roi et de son contraire, le tyran, dans le corpus législatif des Siete Partidas d'Alphonse X le Sage (1252-1284), inspiré de la théorie corporatiste de saint Paul ; puis la vision qu'en donne dans son Livre des États (v. 1330) don Juan Manuel, neveu du roi Sage et prince révolté contre ses successeurs. Dans ce miroir aux princes en forme de questions-réponses, l'exaltation de l'empereur germanique fournit à don Juan les arguments d'une critique en contre-miroir de ce que devrait être le roi castillan pour ses sujets. Un second chapitre examine ensuite ce que les chroniques castillanes des $\mathrm{XIV}^{\mathrm{e}}$ et $\mathrm{XV}^{\mathrm{e}}$ siècles donnent à voir de la Majesté royale. L'Histoire, moralisante et exemplaire, n'est-elle en effet pas l'un des biais par lesquels s'exprime dans la pratique ce à quoi doit aspirer le bon souverain? Un intéressant développement est consacré dans cette optique aux différents traitements historiographiques du crime de lèse-majesté. Un des exemples retenus est celui du meurtre en 1369 du roi Pierre $\mathrm{I}^{\text {er }}$ - 
le Cruel ou le Justicier, autre manifestation de l'ambivalente mémoire historique - par son demi-frère Henri de Trastamare à Montiel, rendu possible par la célèbre trahison de Du Guesclin. Dans les Chroniques de Pero López de Ayala (m. 1407), merino de Pierre $\mathrm{I}^{\mathrm{er}}$ devenu par la suite chancelier d'Henri II, l'événement est en quelque sorte minoré, conséquence symptomatique de l'autojustification que le chancelier tente de donner de sa propre inconstance. Près d'un siècle après les faits, Lope García De Salazar (m. 1476) s'inspire pourtant de ce premier texte dans son Livre des Chances et des Fortunes pour critiquer âprement le crime de Montiel, lequel efface selon lui toute la noblesse du connétable Du Guesclin. Autre exemple, dans les Biographies et Portraits de Fernán Pérez de Guzmán (m. v. 1460), c'est la mainmise du favori du roi Jean II (1407-1454) sur le pouvoir du roi qui est interprétée comme un crime de lèse-majesté. Enfin, c'est au regard sur la Majesté que portent les lettrés qui entourent les souverains qu'est consacré le dernier chapitre de cette partie. Dans les écrits de Hernando del Pulgar ( $m$. v. 1498) et de Diego de Valera (m. 1488), serviteurs de Jean II, Henri IV et des Rois Catholiques pour le second, la réflexion se porte sur les dignités nobiliaires qui accroissent la Majesté royale, et de ce fait sur une exaltation du conseil aux hommes de pouvoir.

3 Après ces développements théoriques, la seconde partie de l'ouvrage se rapporte à l'affichage de la Majesté. Un premier chapitre doit beaucoup aux travaux de José Manuel Nieto Soria ${ }^{2}$ pour rappeler que la Majesté est mise en scène à l'occasion de cérémonies finement orchestrées: avènements et couronnements, entrées royales, funérailles. Puis c'est dans le quotidien que l'on retrouve la « Majesté en action » (chap. 2): dans les sermons et les serments, dans les lois palatines qui réglementent le décorum dont s'entoure le roi, dans les fêtes qui manifestent la prodigalité du souverain envers ses sujets, ou encore la clémence dont il sait faire montre dans la répression des révoltes. Les auteurs font également un sort tout particulier à la Navarre où la rareté des écrits à caractère politique est compensée par l'usage qui est fait des actes diplomatiques comme vecteurs d'une image du pouvoir et de ceux qui le servent, méditation passionnante qui n'est pas sans rappeler les développements qu'a consacrés Amaria Arizaleta à la même problématique dans le contexte du royaume de Castille aux $\mathrm{XII}^{\mathrm{e}}$-XIII ${ }^{\mathrm{e}}$ siècles ${ }^{3}$.

La dernière partie s'attache à l'élaboration des discours sur la souveraineté dans le cadre de la Couronne d'Aragon marquée par la pratique du pactisme. Cette théorie, qui stipule l'existence d'un pacte entre les gouvernants et leurs sujets préexistant à l'autorité politique et la légitimant, contrarie en effet le principe de la Majesté souveraine. Le premier chapitre présente un historique de la notion et de son enracinement progressif depuis le $\mathrm{x}^{\mathrm{e}}$ siècle en Catalogne dans les textes à caractère législatif qui fixent les rapports de négociation entre le roi et ses grands, et sont autant de témoignages du rapport de force changeant entre ces deux pôles de la vie politique. Les deux derniers chapitres s'intéressent ensuite aux discours contrastés qui en émanent et constituent «de véritables histoires parallèles et concurrentes qui conduisent à une véritable guerre des mythes » (p. 159). Ainsi du règne de Ferdinand le Catholique (1479-1516) durant lequel, en pleine période de récupération de la prérogative royale sur le contrôle des institutions, les élaborations intellectuelles sont révélatrices de l'opposition qui sépare les historiens défenseurs de l'absolu monarchique (tels que Gonzalo García de Santa María et Lucio Marineo Sículo appelés officiellement auprès du souverain) et ceux qui expriment l'idée d'une souveraineté 
limitée (Gauberto Fabricio de Vagad dans sa Chronique d'Aragon commanditée par la Diputación du royaume).

5 Si on regrette que les maladresses typographiques, coquilles et autres erreurs de mise en page ne facilitent pas la consultation de ce livre, c'est surtout parce qu'on veut souligner que son grand intérêt réside en ce qu'il se veut un outil pour l'historien en quête de textes et d'exemples - très nombreux et, rappelons-le, traduits en de longs passages. À ce titre, il est également accompagné d'une bibliographie de sources éditées et de travaux offrant une base de documentation substantielle pour qui souhaitera approfondir les thèmes abordés.

\section{NOTES}

1. J.-P. BARRAQUÉ et B. LEROY, Des écrits pour les rois. En Espagne médiévale, la réflexion politique d'Isidore de Séville aux Rois Catholiques, Limoges, 1999.

2. J.M. NIETO SORIA, Ceremonias de la Realeza. Propaganda y legitimación en la Castilla Trastámara, Madrid, 1993.

3. A. ARIZALETA, Les Clercs au palais. Chancellerie et écriture du pouvoir royal (Castille, 1157-1230), Paris, 2010, en ligne [URL : http://e-spanialivres.revues.org/154]. 